\title{
UMA PROPOSTA DE FORMAÇÃO EM CIÊNCIAS E MATEMÁTICA NA PERSPECTIVA INTERDISCIPLINAR: A VISÃO DE LICENCIANDOS DE UM CURSO DE PEDAGOGIA
}

\author{
Priscilla Lucia Cerqueira ${ }^{1}$, Reginaldo Fernando Carneiro ${ }^{2}$ \\ ${ }^{1}$ Mestranda em Educação e licenciada em Química pela Universidade Federal de Juiz de Fora - UFJF. \\ E-mail: priquimica@hotmail.com \\ ${ }^{2}$ Doutor em Educação, Docente da Faculdade de Educação da Universidade Federal de Juiz de Fora - UFJF. E-mail: \\ reginaldo carneiro@yahoo.com.br
}

\section{RESUMO}

A formação inicial de professores dos anos iniciais do Ensino Fundamental - assim como de docentes para o ensino de ciências e matemática - tem estado na pauta de muitos estudos na área da Educação. Este artigo, recorte de uma pesquisa de mestrado, tem como objetivo investigar as percepções de licenciandos em Pedagogia sobre a vivência de proposta de formação em ciências e matemática em uma perspectiva interdisciplinar. Para tanto, desenvolveu-se uma pesquisa qualitativa cujos dados são decorrentes das atividades realizadas pelos estudantes, de um questionário e uma entrevista com os professores formadores que participaram de uma proposta de trabalho interdisciplinar nas disciplinas de Fundamentos Teóricos e Metodológicos e Prática Escolar em Ciências I e Fundamentos Teóricos Metodológicos e Prática Escolar em Matemática I em um curso de Pedagogia de uma universidade pública mineira. A análise dos dados, pautada na teoria da análise de conteúdo, evidenciou que os licenciandos tinham clareza de que a sua formação em ensino de ciências e matemática não deve pautar na perspectiva da transmissão, mas em um processo que busque articular conceitos e conteúdos das diferentes disciplinas. Dessa forma, valorizaram a interdisciplinaridade como possibilidade de integração e como facilitador do processo de ensino e aprendizagem.

Palavras-chave: Formação de Professores. Ciências e matemática. Interdisciplinaridade. Pedagogia.

\section{A PROPOSAL FOR TEACHER EDUCATION IN SCIENCE AND MATHEMATICS IN THE INTERDISCIPLINARY PERSPECTIVE: THE VISION OF UNDERGRADUTES OF A PEDAGOGY COURSE}

\begin{abstract}
Teacher education of the early years of Elementary School - as well as this education for science and mathematics teaching - has been on the agenda of many studies in the area of Education. In this article, part of a masters study, aims to investigate the perceptions of undergraduates in Pedagogy about the experience of education proposal in science and mathematics in an interdisciplinary perspective. To that end, a qualitative research was developed in which we used for data production, the activities carried out by the students, a questionnaire and an interview with the teacher trainers who participated in a proposal of interdisciplinary work carried out in the disciplines of Theoretical and Methodological Foundations and School Practice in Science I and Theoretical and Methodological Foundations and School Practice in Mathematics I of a Pedagogy course of a public university in Minas Gerais. For data analysis, we are guided in the theory of content analysis. The data analyzes, based on the theory of the content analysis, showed that the undergraduates had clarity that their education in science and mathematics teaching could not be based on the perspective of the transmission, but in a process that seeks to articulate the concepts and contents of the different disciplines. In this way, they valued interdisciplinarity as a possibility of integration and as a facilitator of the teaching and learning process.
\end{abstract}

Keywords: Teacher Education. Science and mathematics. Interdisciplinarity. Pedagogy. 


\section{INTRODUÇÃO}

Os cursos de Pedagogia possuem um amplo currículo e têm por objetivo formar profissionais capazes de atuar na Educação Infantil, nos anos iniciais do Ensino Fundamental e também na Educação de Jovens e Adultos. Assim, sua atuação contempla ensinar todos os conteúdos dos componentes curriculares escolares e habilitar para a ocupação de cargos de orientação, supervisão e administração.

Frente tamanha abrangência, Gatti (2000) chama atenção para a falta de especificidade dos objetivos da habilitação nos cursos de Pedagogia, que em alguns momentos define o pedagogo como especialista em educação, em outros como professor ou ainda como estudioso da educação.

Essa variedade de enfoques pode comprometer a formação, especialmente a que se refere à atuação como professor dos anos iniciais do Ensino Fundamental, pois as disciplinas que abordam o ensino de ciências e matemática, por exemplo, são trabalhadas no curso de maneira pulverizada e sem um plano de ação bem delineado. Isso contribui para que as ações pedagógicas sejam também dispersas nas práticas diárias dos professores. Assim, as grades curriculares da Pedagogia precisam ter mais definidas a teorização sobre a Educação, a intervenção na prática docente e a produção de conceitos, processos e modelos, legitimando o curso como instância produtora de saberes e formadora de professores capacitados a colocar em prática o que foi construído durante a formação inicial (CRUZ; AROSA, 2014).

Dados históricos da década de 1950, quando a educação foi marcada pelo caráter tecnicista, evidenciam que ensinar consistia em transmitir conhecimento científico, de maneira que o estudante se tornasse capaz de reproduzilo e, de acordo com Rodrigues (2010), isso reforça a necessidade de repensar a formação do pedagogo. Nessa década, a memorização, prática que pouco estimulava o espírito crítico e reflexivo dos alunos, e a hegemonia da linguagem científica sem utilidade aparente ainda prevaleciam sobre o saber utilitário, popular e cotidiano.

Confirmando essa visão histórica, os Parâmetros Curriculares Nacionais (PCN), mencionam a prática aplicada às disciplinas de ciências:

A preocupação de desenvolver atividades práticas começou a ter presença marcante nos projetos de ensino e nos cursos de formação de professores, tendo sido produzidos vários materiais didáticos desta tendência. 0 objetivo fundamental do ensino de Ciências Naturais passou a ser dar condições para o aluno vivenciar o que se denominava método científico, ou seja, a partir de observações, levantar hipóteses, testá-las, refutá-las e abandoná-las quando fosse o caso, trabalhando de forma a redescobrir

conhecimentos. O método da redescoberta, com sua ênfase no método científico, acompanhou durante muito tempo os objetivos do ensino de Ciências Naturais, levando alguns professores a, inadvertidamente, identificarem metodologia científica como metodologia do ensino de Ciências Naturais, perdendo-se a oportunidade de trabalhar com os estudantes, com maior amplitude e variedade, processos de investigação adequados às condições do aprendizado e abertos a questões de natureza distinta daquelas de interesse estritamente científico. (BRASIL, 1997, p. 19)

Atualmente, muito se vê ainda dessa prática na ação de docentes, pois ela lhes confere segurança, ao propor práticas didáticas para abordar os conteúdos que pouco dominam, uma vez que essa foi a formação oferecida. Contrapondo-se a essa perspectiva, segundo Tardif (2002), mudanças curriculares expressam o desejo de que os cursos de formação de professores ofereçam articulação e equilíbrio entre os conhecimentos produzidos acerca da docência e os múltiplos saberes desenvolvidos por eles em suas práticas diárias. 
As Diretrizes Curriculares Nacionais para o curso de Pedagogia entendem a docência como ação constituída por métodos pedagógicos capazes de estabelecer relações sociais, étnicoraciais e produtivas, a fim de influenciar conceitos, princípios e objetivos da Pedagogia, por meio da articulação entre conhecimentos científicos e culturais, ética e estética oriundos da aprendizagem, da socialização e da construção do conhecimento no diálogo entre as diferentes visões de mundo (BRASIL, 2006).

Dessa forma, um curso que objetiva formar professores precisa garantir a formação e o desenvolvimento de um conjunto de habilidades que possibilitem que o docente seja capaz de atender não apenas a esses objetivos pensados para a formação dos professores, mas também, por consequência, àqueles colocados para os estudantes da Educação Básica (GATTI, 2000). Em meio a tantas reflexões e reestruturações curriculares, as pesquisas sobre a formação de professores têm ganhado cada vez mais visibilidade, tendo em vista seu potencial para produzir conhecimentos e transformações na prática docente.

Para Bassoli (2015), a reflexão sobre a formação do professor tem sido um assunto recorrente nas pesquisas e nas políticas educacionais, porém tem assumido um aspecto de senso comum e vem sendo utilizada como um slogan no meio educacional. Isso traz a necessidade de ser problematizada de fato, saindo do campo das considerações e tornandose objeto de real mudança nos cursos formadores de professores, ou seja, é preciso produzir conhecimento a partir da reflexão sobre a prática. Contudo, quais caminhos devem ser seguidos para isso? Se existem diretrizes produzidas a partir dessas reflexões, por que não as seguir para buscar essa formação?

Assim, pensando em uma abordagem plural que abarque os conceitos e os conteúdos disciplinares para a formação docente por meio de metodologias mais dinâmicas, as Diretrizes Curriculares Nacionais para o curso de Pedagogia (BRASIL, 2006) indicam que as metodologias utilizadas nas disciplinas do curso prezem pela interdisciplinaridade, pois a prática docente disciplinar que ainda vem sendo reproduzida não traz contribuições ao processo de ensino e aprendizagem - revela-se limitada.

Fazenda (2012) explicita que o ensino universitário deveria ser autoexigente, com uma ação interdisciplinar marcada pelo respeito ao ensino organizado por disciplinas e pela constante avaliação das relações existentes entre elas e os problemas da sociedade.

Mas o que compreendemos por interdisciplinaridade? Entendemos que:

existem palavras ligadas entre si pelo radical disciplina:

interdisciplinaridade, muldisciplinaridade, pluridisciplinaridade e transdisciplinaridade. Elas têm em comum o fato de designarem diferentes modos de relação e articulação entre disciplinas ou um processo de integração disciplinar (GATTÁs; FUREGATO, 2007, p. 87, grifos nossos),

Ou seja, ao propor uma ação pedagógica interdisciplinar, não devemos abrir mão do saber disciplinar, mas atentar aos desdobramentos do conhecimento que as disciplinas podem trazer, ao ser integradas.

Lück (2013) discute que, no ensino, a ação disciplinar leva à dissociação entre realidade e sujeito, e essa disfunção se apresenta falha, ao esquematizar conteúdos produzidos de forma desvinculada do cotidiano e das investigações científicas responsáveis pela produção do conhecimento. Isso evidencia uma despreocupação em estabelecer relações entre ideias e realidades, educador e educando e teoria e prática, levando assim à descaracterização do processo pedagógico. Logo, é interessante buscar meios que possibilitem um processo de ensino e aprendizagem mais integrado ao sujeito e ao ambiente no qual está inserido.

No que se refere à formação de professores e ao método interdisciplinar, a relação que deve existir consiste em incorporar os conceitos e os conteúdos de várias disciplinas, proporcionando trocas generalizadas de informações críticas, reorganizando $o$ meio científico a serviço da sociedade e do homem (JAPIASSU, 1976).

Podemos assim dizer que a metodologia interdisciplinar vem reformular a estrutura disciplinar, no sentido de estabelecer conexões que tragam significado à realidade do licenciando e ao mesmo tempo questionem o emprego dos conhecimentos pedagógicos adquiridos durante a formação inicial, o que pode levar pesquisadores 
e educadores a superar a pedagogia da dissociação do saber, favorecendo a descoberta de múltiplas interconexões. Cabe agora estabelecer um sentido mais aprofundado e significativo às experiências pedagógicas, para as quais a interdisciplinaridade tem muito a contribuir.

Lück (2013) salienta ainda a importância de nutrir a perspectiva interdisciplinar com problematizações, a fim de romper com visões fragmentadas, pois do contrário cria-se apenas um novo modismo em educação. Portanto, é preciso cuidado na busca de soluções para problemas encontrados, para que não haja reforço da visão simplificada de mundo, e para que métodos interdisciplinares sejam um paradigma teórico-metodológico que admita ambiguidades e incertezas, e que desse ponto surja a capacidade de construir, ordenar e dar sentido à complexidade que permeia a sociedade e o conhecimento. Esse movimento pode propiciar a construção do senso crítico e reflexivo sobre a sua realidade e o modo de ser e agir em relação ao conhecimento geral e científico.

Thiesen (2008) afirma que a interdisciplinaridade constitui um desafio para as práticas de investigação e de formação de professores, pois essa temática vem sendo tratada sob duas óticas: a epistemológica, considerando seus aspectos de produção do conhecimento, reconstrução e socialização e a ciência e seus paradigmas; e a pedagógica, trazendo a mediação entre o sujeito e a realidade e discutindo a natureza do currículo, do ensino e da aprendizagem escolar.

Assim, ao pensar a interdisciplinaridade como metodologia de formação docente, devemos atentar às duas óticas, pois Tardif (2002) considera que os professores precisam ser reflexivos, pois suas práticas produzem saberes específicos ao seu próprio trabalho e lhes permite repensá-las, partilhá-las, alterá-las, de modo a produzir conhecimentos a partir das particularidades diárias dos estudantes da Educação Básica. De tal modo, a prática profissional torna-se um espaço importante de aprendizagem para os futuros professores, bem como de saberes e metodologias diferentes, o que pode ser favorável à ação interdisciplinar.

Estabelecer um trabalho na perspectiva interdisciplinar provoca certo desconforto, ainda mais quando se trata de mudar a maneira de abordar as disciplinas da formação docente, pois essa proposta foge ao que já está estabelecido, gerando sobrecarga de trabalho e insegurança. Concordamos com Lück (2013), ao reconhecer que, para o desenvolvimento da interdisciplinaridade, são essenciais a prática dialógica, o engajamento e a participação dos professores, a fim de superar a fragmentação do ensino na construção do novo projeto e de sua própria prática individual. Isso certamente é um desafio.

Silva e Pinto (2009) discute que existe, na práxis educacional, uma tradição que se vale da compartimentalização e fragmentação do todo e que implica diretamente no modo como interpretamos e compreendemos o mundo. Muitas vezes, para apreender um objeto, é necessário dividi-lo em partes, o que resulta, em certos casos, em um quebra-cabeça que nem sempre será passível de reconstituição, levando assim à perda de detalhes que podem conduzir a novos conhecimentos. E é o que ocorre na prática docente: cada professor sabe muito sobre a sua especialidade, mas nem sempre a compreende, quando integrada às demais.

Pensando na especificidade e na dificuldade de unir as peças que compõem um conhecimento maior, Ferreira (2012) introduz a ideia de que a interdisciplinaridade é uma proposta que pode ser almejada, mas não deve ser imposta, visto ser um conceito amplo e complexo dentro do processo formativo e que busca extrapolar a disciplinaridade.

Nessa perspectiva, a interdisciplinaridade nos cursos de Pedagogia tem por intenção constituir um campo de investigação específico da própria prática educativa e dos suportes teóricos oriundos das demais ciências da educação, cujo objetivo é a compreensão dos problemas científicos relacionados ao cotidiano do educando (LIBÂNEO, 2005).

Assim, do ponto de vista da totalidade do conhecimento e tomando a interdisciplinaridade como forma de entendimento do mundo e do fazer pedagógico, no sentido de práticas direcionadas a concepções sociais cada vez maiores no âmbito educacional, faz sentido propor movimentos interdisciplinares no ensino superior, com propostas de práticas diferentes para o ensino das disciplinas, a fim de contribuir com a construção dos saberes na formação docente. E permitir, de maneira simultânea, que o licenciando vivencie uma prática que pode ser utilizada para planejar e realizar suas atividades docentes na escola de forma interdisciplinar, 
buscando conectar saberes científicos e cotidianos dos alunos.

A partir do exposto, consideramos que uma investigação sobre propostas interdisciplinares que não ignoram os saberes disciplinares e científicos, mas propõem interatividade e construção conjunta desses, tem muito a contribuir com os processos de formação docente. De acordo com Mizukami (2008, p. 173), As pesquisas que tomam os saberes docentes como objeto de estudo já rompem com a concepção de que o bom professor é aquele que tem apenas o domínio do conteúdo. Não significa, porém, negar a importância dos conteúdos, mas partir do pressuposto de que o saber docente vai além dessa única dimensão do conhecimento.

A proposta que discutiremos neste artigo não pretende definir interdisciplinaridade epistemologicamente, por ser um conceito polissêmico, mas se propõe, a partir dos sentidos já existentes, a fazer novas releituras das teorias e estruturar práticas que possam ser desenvolvidas na formação de professores.

Assim, temos como objetivo investigar as percepções de licenciandos em Pedagogia sobre a vivência de proposta de formação em ciências e matemática em uma perspectiva interdisciplinar. Para tanto, acompanhamos uma proposta de trabalho nas disciplinas de Fundamentos Teóricos e Metodológicos e Prática Escolar em Ciências I e Fundamentos Teóricos Metodológicos e Prática Escolar em Matemática I, oferecidas no $4 .^{\circ}$ período de um curso de Pedagogia de uma universidade pública mineira.

\section{METODOLOGIA}

Martins (2004) apresenta uma discussão relevante sobre metodologia de pesquisa, que por vezes passa desapercebida nos trabalhos de investigação, visto que o foco sempre recai sobre a questão problema. A autora aponta que o plano metodológico está a serviço da pesquisa e, por isso, sujeito não só às técnicas empregadas, mas também a uma discussão teórica. Na pesquisa acadêmica, o pesquisador depara-se constantemente com a necessidade de conhecer e discutir o caminho a percorrer, a fim de planejar de que forma transformar o fenômeno de investigação em um objeto de pesquisa.

Percebemos o ensino superior como um espaço que permite ainda desenvolver pesquisas que discutam e contribuam com a formação docente. Segundo Chaer, Diniz e Ribeiro (2011, p. 251),

os alunos que ingressam nas universidades vêm de uma realidade em que não há o tão necessário estímulo à construção do conhecimento. Pelo contrário, até o ensino médio, o estudante brasileiro é, via de regra, treinado para memorizar e repetir fórmulas que, se devidamente apreendidas, serão sua chance de aprovação no exame vestibular, o que adviria ideologia de dominação, autoritária, que predomina na escola do mundo capitalista [...]. Surge, então, após o ingresso no Ensino Superior, a reviravolta da realidade. 0 aluno, até então mero ator, encenando aquilo que the era determinado, precisa passar a ser também autor de sua história acadêmica, participando da elaboração do conhecimento.

E é com essa visão que, neste artigo, buscamos fazer com que os licenciandos participantes da pesquisa saíssem da cômoda posição de espectadores e se tornassem sujeitos ativos do processo de construção do próprio conhecimento em ciências e matemática, contribuindo, no âmbito das pesquisas educacionais, com a formação docente e também com a sua própria, visto que a participação efetiva trouxe um processo reflexivo ao estudante em contexto.

Assim, desenvolvemos uma pesquisa qualitativa (BOGDAN; BIKLEN, 1994), em que utilizamos, para a produção de dados, as atividades, o questionário, a entrevista e a observação das aulas de ciências e matemática. Contudo, neste texto vamos discutir somente os 
dados referentes ao questionário respondido pelos licenciandos.

Gil (2008, p. 121) discute que o questionário pode ser compreendido como um artifício de investigação, no qual um conjunto de questões é apresentado às pessoas, com intuito de obter informações sobre "conhecimentos, crenças, sentimentos, valores, interesses, expectativas, temores, comportamento presente ou passado, situações vivenciadas e etc.".

Considerando que buscamos apreender as percepções dos licenciandos sobre a proposta de trabalho interdisciplinar com ciências e matemática, optamos por utilizar questões abertas, por entendermos que esse tipo de pergunta permite liberdade de resposta ao informante.

Antes de iniciarmos a observação nas disciplinas, submetemos o projeto de pesquisa ao Comitê de Ética em Pesquisas com Seres Humanos $^{1}$ e, após aprovação, seguimos com a coleta dos dados.

Para compreensão do percurso metodológico adotado, organizamos esta exposição em três momentos:

Momento 1: Escolha das disciplinas do curso de Pedagogia para a investigação sobre a formação docente a partir da perspectiva interdisciplinar entre ciências e matemática.

O curso de Pedagogia investigado tem duas disciplinas que tem como objetivo discutir aspectos relacionados ao ensino e aprendizagem de matemática nos anos iniciais e outras duas referentes à ciências nesse nível de ensino, com carga horária de 60 horas cada uma. Essas disciplinas fazem parte do eixo denominado de saberes escolares ${ }^{2}$.

As disciplinas Fundamentos Teóricos Metodológicos e Prática Escolar em Matemática I e II e a disciplina Fundamentos Teóricos Metodológicos e Prática Escolar em Ciências I são obrigatórias aos estudantes. A disciplina de Fundamentos Teóricos Metodológicos e Prática Escolar em Ciências II é eletiva.

Por isso, escolhemos, para esta investigação, as disciplinas Fundamentos Teóricos e Metodológicos e Prática Escolar em Ciências I e Fundamentos Teóricos Metodológicos e Prática Escolar em Matemática I, por serem obrigatórias aos estudantes do $4 .^{\circ}$ período de licenciatura em Pedagogia e por percebermos a consonância entre o plano de ensino dessas disciplinas e as proposições das Diretrizes Curriculares Nacionais para os cursos de Pedagogia, quanto ao que ensinar e a como ensinar sobre os conteúdos e conceitos de ciências e matemática para os anos iniciais do Ensino Fundamental.

Os estudos em educação em ciências e educação matemática evidenciam que disciplinas que abordam questões de ciências e matemática em cursos de Pedagogia apresentam carga horária reduzida (CURI, 2005; MARSIGLIA, 2011) ou ainda nem são oferecidas como explicitado por Batista e Lanner (2007) que em um levantamento realizado em 316 cursos, 45\% não tinha em seus currículos disciplinas voltadas para a formação matemática do futuro professor, por exemplo.

Embora esse curso de Pedagogia tenha em sua grade curricular duas disciplinas de ciências e duas de matemática, representando juntas $7,5 \%$ da carga total do curso que é de 3220 horas, ainda é um número pequeno de horas e um dado que vai ao encontro do que é apresentado pela literatura da área.

Momento 2: Assinatura do termo de consentimento livre e esclarecido (TCLE).

O TCLE é um documento exigido pelo Comitê de Ética em Pesquisas com Seres Humanos (CEP), no qual o público pesquisado é convidado a participar como voluntário da pesquisa e é informado sobre os objetivos, as atividades, os riscos e os benefícios de participação no estudo.

Momento 3: Escolha de temas.

Os professores propuseram, no início das disciplinas, que houvesse encontros conjuntos em que fossem abordados conceitos e conteúdos de ciências e matemática a partir de temas escolhidos pelos próprios licenciandos. Em uma discussão coletiva, foram escolhidos os temas: Astronomia; Tecnologia; Número de ouro e Relógio de Sol.

Ao longo do semestre, foram realizados esses encontros com os professores das duas disciplinas de que os licenciandos participaram, desenvolvendo atividades que englobavam discussões sobre ciências e matemática nos anos iniciais.

Apresentamos a seguir um quadro com as temáticas e algumas das atividades desenvolvidas em cada uma delas.

\footnotetext{
${ }^{1}$ Parecer de aprovação $n^{\circ} 2.583 .411$.

${ }^{2}$ Informações retiradas da página na internet do curso.
} 
Quadro 1. temas e atividades desenvolvidas nas disciplinas

\begin{tabular}{|l|l|}
\hline Temas & \multicolumn{1}{c|}{ Atividades } \\
\hline \multirow{3}{*}{ Astronomia } & - Discussão de textos \\
& - Exibição de vídeo Pálido Ponto Azul \\
& - Diferentes calendários \\
\hline \multirow{3}{*}{ Tecnologia } & - Discussão de textos \\
& - Possibilidades de utilização das tecnologias \\
& - Star Walk, Google Earth e Sushi Monster \\
& - Um episódio na vida de Joãozinho da Maré \\
& - Aplicativos disponíveis na Internet \\
\hline \multirow{3}{*}{ Números de Ouro } & - Texto “Eu sou o corpo humano" \\
& - Homem Vitruviano \\
& - Corpo Humano \\
& - Sequência de Fibonacci \\
\hline \multirow{2}{*}{ Relógio de Sol } & - Vídeo sobre como construir relógio de sol \\
& - Pontos cardeais \\
& - Construção do relógio de Sol \\
\hline
\end{tabular}

Fonte: Autores (2018)

Momento 4: Aplicação do questionário ao final das disciplinas.

Aos estudantes matriculados nas disciplinas de ciências e matemática que concordaram em participar da pesquisa, foi aplicado um questionário com foco nas atividades nelas desenvolvidas com o intuito de caracterizar os alunos envolvidos no processo de investigação - licenciandos do $4 .^{\circ}$ período do curso de Pedagogia de uma universidade pública mineira, majoritariamente do sexo feminino e que já cursaram disciplinas de estágio, ou seja, já tiveram algum contato com a sala de aula. Todos estavam cursando pela primeira vez a disciplina de ciências e de matemática.

Os dados produzidos foram analisados com base na teoria da análise de conteúdo, que reúne técnicas que se complementam, ao sistematizar e explicar o conteúdo da mensagem, e tornam explícito o significado pretendido pelo emissor, considerando o contexto na qual foi produzido.

Bardin (2009, p. 44) explicita que a análise de conteúdo é

um conjunto de técnicas

de análise das

comunicações visando

obter procedimentos

sistemáticos e objectivos de descrição do conteúdo das mensagens indicadores (quantitativos ou não) que permitam a inferência de conhecimentos relativos às condições de produção/recepção (variáveis inferidas) desta mensagem.

Nesse sentido, Franco (2008) considera que a vantagem desse método analítico está na produção de sentidos e significados derivados da diversidade de amostragem presente no amplo universo de coleta de dados. Assim, a investigação aqui proposta pressupõe a categorização, a descrição e a interpretação como etapas essenciais de análise, que podem contribuir para apreendermos a formação de professores a partir da perspectiva do licenciando que vivenciou a prática interdisciplinar.

\section{RESULTADOS}

A turma era constituída de 38 alunos, dos quais 26 assinaram o TCLE, aceitando participar da pesquisa, e 16 responderam o questionário.

As questões foram elaboradas, considerando os objetivos da pesquisa e as práticas de ensino vivenciadas no decorrer do semestre letivo. Foram sete perguntas abertas, que abordaram as vivências nas disciplinas de ciências e matemática; a forma como as disciplinas foram oferecidas, de maneira a se complementar; os temas abordados e os recursos utilizados; a possibilidade de os conteúdos serem trabalhados conjuntamente; a ocorrência - ou não - de relações entre os saberes de ciências e matemática e de contribuição das disciplinas; e a perspectiva de o estudante, como docente, 
utilizar uma proposta interdisciplinar em suas práticas futuras.

As respostas às perguntas do questionário sobre a vivência e o trabalho interdisciplinar proposto à turma de futuros professores do Ensino Fundamental que cursaram as disciplinas foram analisadas e categorizadas, permitindo explorar as falas dos participantes da pesquisa e compreender os elementos categóricos a que podem estar associadas.

Segundo Bardin (2009), a categorização é um procedimento de classificação que implica na investigação do que cada um dos elementos tem em comum com outros, de modo a agrupá-los. Dessa forma, a categorização pretende levar à compreensão de como as vivências de práticas interdisciplinares na formação inicial, na perspectiva dos estudantes, podem ter contribuído para a formação do licenciando em ciências e matemática e possibilitado inferências sobre o que é possível e o que se faz necessário discutir no processo de ensino e aprendizagem.

Dentre as sete questões do questionário, escolhemos quatro para analisar a perspectiva dos futuros professores dos anos iniciais. A primeira questão solicitou que avaliassem a proposta resultante de algumas aulas das disciplinas terem sido pensadas, planejadas e desenvolvidas em conjunto pelos professores, de maneira a se complementarem. $E$ as outras três questões foram elaboradas para obter a justificativa da resposta dada à questão anterior. Essas questões fizeram alusão aos temas trabalhados, aos recursos utilizados nas aulas, às possíveis relações estabelecidas entre as disciplinas e à possibilidade de sua utilização em suas práticas futuras.

Os 16 licenciandos que responderam ao questionário afirmaram que a experiência de participar de aulas interdisciplinares de ciências e matemática foi produtiva, positiva e enriquecedora, dentre outros atributos. Houve apenas uma participante que avaliou a proposta das aulas como "muito relevante", porém criticou as aulas de ciências em relação aos temas e aos recursos utilizados, por ter sentido falta de uma abordagem mais conteudista. Não houve, na sua fala, expressões negativas em relação aos critérios e aos recursos empregados, ela apenas mencionou ter sentido falta de algo que pudesse ter complementado a proposta.
A seguir, algumas falas dos licenciandos, que expressam o que aqui mencionamos (grifos nossos):

De início, pareceu que seria confuso e impossível de ocorrer. Mas já na primeira aula, já foi possível perceber que é tranquilo e super viável algumas aulas em conjunto. (Milena) ${ }^{3}$

Avalio como ponto de partida para futuros trabalhos, e como forma de testar, errar, compreender como aulas assim podem ser cada vez mais potencializadas $e$ interessantes aos alunos. (Luna)

Como disse anteriormente, foi inovador e, por ser algo novo, pareceu-me estranho no início; porém enquanto o processo foi se desenvolvendo pude perceber $o$ quanto $a$ proposta era construtiva. Avalio como algo enriquecedor e que vale a pena ser feito. (Elis)

Acredito que seja fundamental para a educação, permitir que os alunos vejam como as disciplinas interagem entre si, tirando do imaginário de que cada ciência tem sua esfera desvinculada da outra. (Gustavo)

A proposta deu bastante abertura para os assuntos que nós, alunos indagamos durante as aulas. $\mathrm{O}$ que evidenciou $a$ importância dos questionamentos. (Dinorá Solerio)

As proposta foi muito relevante. Trabalhar em

\footnotetext{
${ }^{3}$ Os nomes utilizados para identificar os participantes da pesquisa foram escolhidos pelos próprios licenciandos.
} 
conjunto duas matérias é trabalhar de forma interdisciplinar conteúdos diversos que podem e devem estar associados. $A$ ideia e duas disciplinas que conversam entre si serem dadas juntas é muito interessante e nos abre o olhar para trabalhar assim quando estivermos em sala de aula. (Maya)

Nessa experiência de formação de professores por meio de um trabalho interdisciplinar, podemos destacar reflexões a respeito da proposta e ações futuras dos licenciandos, quando atuarem na educação básica, haja vista as respostas dadas às questões selecionadas para justificar a avaliação da estratégia didática abordada durante as aulas.

Assim, apresentamos algumas das respostas obtidas sobre as questões: "Hoje você consegue estabelecer uma relação entre ciências e matemática? Se sim, qual seria? Foi uma contribuição das disciplinas mencionadas anteriormente?", "Futuramente, enquanto professor(a) do Ensino Fundamental, como você pretende trabalhar as disciplinas de ciências e matemática? Justifique sua resposta."

Consigo estabelecer que as disciplinas se comunicam bastante, principalmente nas séries iniciais. O trabalho final, sobretudo, mostrou a facilidade de unir matérias diferentes em um mesmo assunto.

Pretendo unir ao máximo, assim fica mais divertido para os alunos e para mim, como professora. (Milena)

A relação do trabalho com os assuntos da ciência, da natureza, seres humanos, animais, entre outros, com os números, operações e grandezas da matemática. E foi sim uma contribuição das disciplinas de matemática e ciências.

Pretendo fazer como foi feito em nossas aulas na universidade, buscar fazer aulas separadas, algumas conjuntas evidenciando sempre aos meus alunos que esse trabalho pode ser feito, que os conteúdos não estão isolados como infelizmente foi passado para mim no meu ensino fundamental e em praticamente toda minha vida escolar. (Francislene)

Consigo estabelecer uma relação sim. Nas aulas de astronomia, por exemplo, é possível trabalhar tanto ciência quanto matemática usando cálculos de distância, ângulo e velocidade e o sistema solar. Eu já havia pensado nessa possibilidade e nas aulas conjuntas vi que é possível.

Claro que sim! Eu amo ciências e aprendi propostas para trabalhar tanto as duas disciplinas conjuntas, quanto isoladas. Um meio de trabalhar com ambas disciplinas é usar o cotidiano dos alunos e a comunidade onde moram, pois acredito que desta forma há uma aproximação de sua realidade trazendo a afetividade para a sala de aula e tendo como consequência maior desempenho e aprendizagem dos alunos. (Maria Flor)

Sim, hoje é possível ter um olhar muito mais profundo e crítico em relação ao envolvimento das duas disciplinas e até mesmo outras. Todo tipo de ser, estrutura química, ou reações físicas conhecidas pela ciência, também podem ser vistos pela matemática, o grande problema do ensino hoje é não fazer questão 
nenhuma de mostrar isso

aos seus alunos, aumentando ainda mais o abismo entre elas.

Buscando sempre apoio dos colegas, envolvendo a turma. Durante a disciplina tivemos ao longo dos trabalhos apresentados muitas ideias que poderemos utilizar em aulas posteriores. É importante sempre ter um olhar atento para os interesses dos alunos e nas possibilidades de envolver outras disciplinas para trabalho em conjunto. (Gustavo)

Sim, consigo perceber vários assuntos (interessantes) que podem ser trabalhados nessas disciplinas conjuntamente, as dúvidas que os alunos trazem na maior parte das vezes podem ser estopim para um trabalho interdisciplinar. Sem dúvida, comecei a pensar na interdisciplinaridade de fato depois desse projeto.

Pretendo fazer com que os alunos conheçam essas disciplinas mais a fundo, sem a visão tradicionalista da matemática chata e difícil e a ciência do cientista maluco. (Joceane)

Sim. Por exemplo, o estudo do universo que seria só em ciências, dá para trabalhar em matemática também. Sim, eu não teria pensado nisso, trabalhar em conjunto, se não tivesse feito essas matérias.

A matemática sempre foi minha área de interesse para atuar, sempre gostei da matéria e de ensinar. Ciências pode ser um caso a pensar, mas caso eu opte por atuar nessas áreas, eu trabalharia em conjunto sim, para ser mais interessante para as crianças e para mim. (Luana)

Sim. Relação do corpo com a natureza envolve não somente ciências, mas [também] matemática. Quando falamos de astronomia, que a princípio eu entenderia como um tema da ciências e vimos que tem todo um envolvimento da Matemática também. Essa relação se deu sim através das disciplinas.

Sempre de forma lúdica e tentando ao máximo simplificar o conteúdo de uma forma que facilite ao aluno sua compreensão. Buscar atividades do dia a dia como exemplos, entre outros. (Maya)

A partir dessas respostas, passamos a discutir e a analisá-las com base em nosso referencial teórico.

\section{DISCUSSÃO}

A proposta interdisciplinar desenvolvida na formação inicial de professores que atuarão nos primeiros anos do Ensino Fundamental é uma tentativa de mudança e um avanço nas práticas docentes. A análise das falas dos estudantes permitiu identificar que essa prática foi inédita na sua formação até aquele momento do curso.

Optamos por não utilizar no questionário expressões como "interdisciplinar" e "interdisciplinaridade", para não influenciar nas impressões dos estudantes, porém as identificamos nas respostas, o que nos permitiu inferir que a proposta foi bem recebida e compreendida pelos licenciandos. Dentre os 16 questionários respondidos, 10 trouxeram os termos "interdisciplinar" ou "interdisciplinaridade" em uma ou mais respostas dadas entre as 7 questões. Nos outros 6 questionários respondidos, em que as expressões propriamente ditas não apareceram, as falas fizeram alusão a elas.

Lück (2013, p. 44) apresenta algumas proposições acerca da interdisciplinaridade que 
são pertinentes nessa discussão e se referem às várias descrições do sentido e do significado prático da interdisciplinaridade. Uma delas, a interdisciplinaridade paradigmática, envolve a "visão de conjunto de uma realidade, mediante permanente associação das diferentes dimensões (disciplinas) com que pode ser analisada; visão global e não fragmentada; uma ótica que abrange todos os aspectos da produção e uso do conhecimento".

A interdisciplinaridade processual pressupõe, conforme Lück (2013, p. 45): convergência de várias disciplinas com vistas à resolução de um problema cujo enfoque teórico está, de algum modo, ligado ao da ação ou da decisão; articulação orgânica de conteúdos e de disciplinas; instauração de diálogo entre várias disciplinas, buscando a unidade do saber; busca de interação entre duas ou mais disciplinas; movimento de interação de áreas de conhecimento diferentes, visando à superação da visão fragmentada da realidade; metodologia pluralista, caracterizada por crítica permanente; movimento do saber orientado pela busca permanente de relações recíprocas de conhecimento, de maneira a deslocar suas fronteiras; via possível de ampliação do exercício crítico; complementaridade e integração de áreas diferentes de estudo.

A interdisciplinaridade de cunho técnico apresenta "uma ferramenta utilizada para superar a fragmentação de ensino; uma ferramenta utilizada para produzir novos conhecimentos, pela integração dos já produzidos" (LÜCK, 2013, p. 45). E, por fim, a de resultados, que traz:

Superação do saber disciplinar; síntese de duas ou mais disciplinas, de modo a estabelecer um novo nível de representação da
realidade, mais
abrangente, de que
resulta o estabelecimento
de novas relações;
formação do cidadão do
mundo, quer dizer,
pessoas abertas à
pluralidade de
paradigmas, de horizontes
culturais. (LÜCK, 2013, p.
46)

As ponderações de Lück permitem constatar que a interdisciplinaridade foi vivenciada por cada um dos licenciandos, promovendo uma nova visão da realidade, um novo modo de pensar, mais crítico e reflexivo quanto à prática docente e ao processo de ensino e aprendizagem dos conteúdos científicos trabalhados a partir da troca, da reciprocidade e da integração entre as diferentes áreas e os sujeitos envolvidos no processo.

Um aspecto importante destacado pelos licenciandos é mostrar para os alunos dos anos iniciais que as ciências têm relação umas com as outras e que conteúdos e conceitos podem ser abordados a partir de um tema.

Logo, os dados obtidos permitem afirmar que a vivência da proposta interdisciplinar pelos licenciandos trouxe contribuições ao processo de formação docente, visto que lhes permitiu perceber a possibilidade de integração dos conceitos e dos conteúdos para serem trabalhados na escola, como uma maneira de romper com a fragmentação disciplinar.

Nesse sentido, o objetivo das aulas promoveu esse contato com uma prática interdisciplinar que, a princípio, trouxe medo e insegurança a alguns estudantes, por nunca terem vivenciado essa proposta de trabalho. Importante destacar a força da cultura escolar de ensinar muitos conteúdos, aspecto que foi destacado como ponto negativo do trabalho, pois, para uma das licenciandas, faltou a abordagem dos conteúdos.

Além disso, comentários destacados pelos futuros professores de que o trabalho interdisciplinar nos anos iniciais pode surgir a partir das dúvidas dos alunos e de questões presentes no cotidiano deles são uma maneira de evitar a proposta de trabalhos que sejam meramente de justaposição de conteúdos, e não de interdisciplinaridade de fato. 
Também foi possível aos estudantes perceberem que as aulas em conjunto não compunham um ensino transmissivo, em que iriam reproduzir as atividades na sala de aula dos primeiros anos, exatamente como tiveram em sua formação. Mas, por ser esse um processo de construção do conhecimento e de aprendizagem pelo qual todos passaram ao explorar os saberes científicos e matemáticos, permitiu a eles ampliar seu campo de ação e compreender conteúdos e conceitos que não aprenderam na escola.

É importante que o licenciando, após essa vivência, continue buscando trabalhar práticas interdisciplinares e reflita, planeje e utilize essas estratégias, de maneira a desenvolver as capacidades científicas, sociais e culturais suas e de seus alunos.

\section{CONCLUSÕES}

Este artigo teve como objetivo investigar as percepções de licenciandos em Pedagogia sobre a vivência de proposta de formação em ciências e matemática em uma perspectiva interdisciplinar. Para tanto, apresentamos as discussões a partir das respostas a um questionário respondido por futuros professores ao final das disciplinas que abordaram aspectos de ciências e matemática.

Com os resultados obtidos foi possível verificar que o trabalho interdisciplinar, na perspectiva dos estudantes, é possível, integrador e facilitador do processo de ensino e aprendizagem, além de ser agradável e instigador da busca por novos conhecimentos, pois favorece que o professor deixe de lado a fragmentação das disciplinas e permite a socialização dos conhecimentos.

No que se refere à visão do licenciando sobre a vivência interdisciplinar durante a sua formação inicial, a proposta alcançou seu objetivo: ampliou possibilidades de trabalho didático, de conhecimentos científicos e trocas profissionais e pessoais; despertou o olhar do futuro professor para novas maneiras de trabalho em sala de aula; e o incentivou a enfrentar os desafios da realidade docente que encontrará na escola.

Tendo como parâmetros as próprias falas dos licenciandos, ao afirmarem que o pensar e o agir interdisciplinar se apoiam no princípio de que nenhuma fonte de conhecimento é, em si mesma, completa e que, pelo diálogo com outras formas de conhecimento, de maneiras de interpretar, emergem novos desdobramentos na compreensão da realidade e na sua representação. Nesse contexto, os licenciandos explicitaram que a interdisciplinaridade ressalta a importância e a necessidade da dissociação entre teoria e prática.

Dessa forma, a interdisciplinaridade é um processo que envolve a integração e o engajamento de educadores, em um trabalho conjunto de interação das disciplinas do currículo escolar entre si e com a realidade, de modo a superar a fragmentação do ensino.

Esperamos que essas reflexões contribuam com a formação inicial e continuada de professores dos anos iniciais do Ensino Fundamental.

\section{AGRADECIMENTO}

Agradecemos o apoio financeiro da CAPES para o desenvolvimento da pesquisa de mestrado.

\section{REFERÊNCIAS}

BARDIN, L. Análise de conteúdo. Lisboa: Edições 70, 2009.

BASSOLI, F. A reflexão e a pesquisa na formação e na prática dos professores: realidade, slogan ou ilusão? In: BASSOLI, F.; LOPES, J. G. S.; CESAR, E. T. (Org.). Contribuições de um centro de ciências para a formação continuada de professores. São Paulo: Livraria da Física, 2015. p.17-38.

BATISTA, F. D.; LANNER, A. R. A formação para o ensino de matemática nos currículos de pedagogia das instituições de ensino superior do Estado de São Paulo: características e abordagens. In: CONGRESSO DE LEITURA DO BRASIL, 16, 2007, Campinas. Anais... Campinas, 2007, p. 1-11. Disponível em: <http://www.alb.com.br>. Acesso em: 10 jul. 2008.

BOGDAN, R. C.; BIKLEN, S. K. Investigação qualitativa em educação: uma introdução à teoria e aos métodos. Porto: Porto Editora, 1994. 336p.

BRASIL. Ministério da Educação. Secretaria de Educação Fundamental. Parâmetros Curriculares Nacionais. Brasília: MEC, 1997.

BRASIL. Resolução CNE/CP № 1, de 15 de maio de 2006. Institui Diretrizes Curriculares Nacionais para o Curso de Licenciatura em Pedagogia. Brasília: MEC, 2006. 
CHAER, G.; DINIZ, R. R. P.; RIBEIRO, E. A. A técnica do questionário na pesquisa educacional. Evidência, Araxá, v. 7, n. 7, p. 251-266, 2011.

CRUZ, G. B.; AROSA, A. C. C. A formação do pedagogo docente no curso de pedagogia. Revista Educação e Cultura Contemporânea, v. 11, n. 26. p.30-68, 2014.

CURI, E. A formação matemática de professores dos anos iniciais do ensino fundamental face às novas demandas brasileiras. Revista Iberoamericana de Educación. v. 37, n. 5, p. 1-10, 2005. Disponível em: <http://www.rieoei.org/delos lectores/1117Curi.pdf>. Acesso em: 28 jul. 2011.

FAZENDA, I. C. A. Interdisciplinaridade: história, teoria e pesquisa. Campinas: Papirus, 2012.

FERREIRA, V. F. A. Interdisciplinaridade é desejável, mas o modelo não pode ser imposto. Química Nova, v. 35, n. 10, p.1, 2012.

FRANCO, M. L. P. B. Análise de conteúdo. Brasília: Liber Livro, 2008.

GATTÁS, M. L. B.; FUREgATO, A. R. F. A interdisciplinaridade na Educação. Revista RENE, Fortaleza, v. 8, n. 1, p. 85-91, jan./abr. 2007.

GATTI, B. A. Formação de professores: problemas e movimentos de renovação. Campinas: Autores Associados, 2000.

GIL, A. C. Métodos e técnicas de pesquisa social. São Paulo: Atlas, 2008.

JAPIASSU, H. Interdisciplinaridade e patologia do saber. Rio de Janeiro: Imago, 1976.

LIBÂNEO, J. C. As teorias pedagógicas modernas revisitadas pelo debate contemporâneo na Educação. In: LIBÂNEO, J. C.; SANTOS, A. Educação na era do conhecimento em rede $e$ transdisciplinaridade. Campinas: Alínea, 2005. p. 19-62.

LÜCK, H. Pedagogia interdisciplinar: fundamentos teóricos metodológicos. Petrópolis: Vozes, 2013.

MARSILGLIA, A. C. G. A prática pedagógica histórico-crítica na educação infantil e no ensino fundamental. Campinas: Autores Associados,
2011.

MARTINS, H. H. T. S. Metodologia qualitativa de pesquisa. Educação e Pesquisa, São Paulo, v. 30, n. 2, p. 289-300, maio/ago. 2004.

MIZUKAMI, M. G. N. Aprendizagem da docência: conhecimento específico, contextos e práticas pedagógicas. In: NACARATO, A. M.; PAIVA, M. A. V. (Org.). A formação do professor que ensina matemática: perspectiva e pesquisas. Belo Horizonte: Autêntica, 2008. p. 213-231.

RODRIGUES, A. C. Ciências da natureza. In: MICARELLO, H. (Org.). Formação em rede. Juiz de Fora: FEME, 2010.

SILVA, L. H.; PINTO, F. N. P. Interdisciplinaridade: as práticas possíveis. Revista Querubim, 2009, v. 5, p. 1-18. Disponível em: <http://www.uff.br/feuffrevistaquerubim/ images/arquivos/artigos/interdisciplinaridade_en tre_teorias_e_práticas.pdf $>$. Acesso em: 04 jan. 2018.

TARDIF, M. Saberes docentes e formação profissional. Petrópolis: Vozes, 2002.

THIESEN, J. S. Interdisciplinaridade como um movimento articulador no processo ensinoaprendizagem. Revista Brasileira de Educação, Rio de Janeiro, v. 13, n. 39, p.1-11 set./dez. 2008.

Recebido para avaliação: 09/09/2018

Revisado em: 04/12/2018

Aceite Final: 05/12/2018 